\title{
INFLUÊNCIAS DAS POLÍTICAS PÚBLICAS NO ENSINO CONTÁBIL E NO ENSINO COMERCIAL BRASILEIROS (1808-2015)
}

\author{
Nelson Lambert de Andrade ${ }^{1}$ \\ Frederico Efigênio de Carvalho Morais ${ }^{2}$ \\ Lariana Paula Pinto ${ }^{3}$
}

\begin{abstract}
RESUMO: Este artigo teve como objetivo contribuir com a compreensão do surgimento e evolução do ensino contábil no Brasil, inserido no contexto da educação profissional, por meio do histórico de sua criação. Visou conhecer o desenvolvimento e a evolução deste ensino, desde 1808 a 2015, diante das políticas públicas que nortearam a profissão e o ensino contábil até ser reconhecido como bacharelado em Ciências Contábeis. Como metodologia de pesquisa, foi realizado um estudo bibliográfico e documental que buscou destacar as principais alterações relacionadas a esse ensino. Pode-se considerar que este estudo contribui para melhor entendimento de como esse ensino evoluiu no Brasil, ao mostrar os principais marcos que influenciaram a profissão e o ensino contábil que foi se adaptando de acordo com as necessidades demandadas pelo mercado econômico e político, em cada época que atravessou.
\end{abstract}

Palavras-chave: Educação Comercial. Conselho Federal de Contabilidade. Ciências Contábeis.

\section{INFLUENCES OF PUBLIC POLICIES ON BRAZILIAN ACCOUNTING TEACHING AND COMMERCIAL TEACHING (1808-2015)}

ABSTRACT: This paper aimed to contribute to the understanding of the emergence and evolution of accounting education in Brazil, inserted in the context of

\footnotetext{
${ }^{1}$ Doutor em Educação (Currículo) pela Pontifícia Universidade Católica de São Paulo (2014). Mestre em Ciências da Linguagem pela Universidade do Vale do Sapucaí (Univás)-MG em 2007. Graduado em Administração de Empresas (1972) e em Ciências Contábeis (1974) pela Faculdade de Economia e Finanças do Rio de Janeiro. Atualmente é professor permanente do Mestrado em Educação da Univás. E-mail: nelsonandrade@univas.edu.br

2 Mestre em Educação pela Univás, especialista em Gestão de Tributos e Planejamento Tributário pela Universidade Vale do Rio Verde de Três Corações-Unincor; graduado em Ciências Contábeis pela Faculdade Cenecista de Varginha/MG. Atualmente é professor do curso de Ciências Contábeis da Univás. E-mail: fredericomorais@univas.edu.br

${ }^{3}$ Doutora e Mestre pelo Programa de Pós Graduação Stricto Sensu em Psicologia, área de concentração em Avaliação Psicológica, da Universidade São Francisco/SP. Psicóloga pela Univás. Atualmente é professora do Mestrado em Educação e do curso de graduação em Psicologia na Univás. E-mail: proflariana.paula@univas.edu.br
} 
professional education, through the history of its creation. It aimed to know the development and evolution of this teaching, from 1808 to 2015, in the face of public policies that guided the profession and accounting education until it was recognized as a Bachelor of Science in Accounting. As a research methodology, a bibliographic and documentary study was carried out that sought to highlight the main changes related to this teaching. It can be considered that this study contributes to a better understanding of how this teaching evolved in Brazil, by showing the main milestones that influenced the profession and the accounting education that was adapting according to the needs demanded by the economic and political market, in each time it has gone through.

Keywords: Commercial Education. Federal Council of Accounting. Accounting Sciences.

\section{INFLUENCIAS DE LAS POLÍTICAS PÚBLICAS EN LA CONTABILIDAD Y EDUCACIÓN COMERCIAL BRASILEÑA (1808-2015)}

RESUMEN: Este artículo tuvo como objetivo contribuir a la comprensión del surgimiento y evolución de la educación contable en Brasil, insertada en el contexto de la educación profesional, a través de la historia de su creación. Se apuntó a conocer el desarrollo y evolución de esta docencia, desde 1808 hasta 2015, de cara a las políticas públicas que orientaron la profesión y la formación contable hasta que fue reconocida como Licenciada en Ciencias Contables. Como metodología de investigación se realizó un estudio bibliográfico y documental que buscó destacar los principales cambios relacionados con esta enseñanza. Se puede considerar que este estudio contribuye a una mejor comprensión de cómo evolucionó esta enseñanza en Brasil, al mostrar los principales hitos que influyeron en la profesión y la enseñanza contable que se fue adaptando de acuerdo a las necesidades demandadas por el mercado económico y político, en cada tiempo que ha pasado.

Palabras clave: Educación Comercial. Consejo Federal de Contabilidad. Ciencias Contables.

\section{Introdução}

Este artigo objetivou contribuir com a compreensão do surgimento e evolução do ensino contábil no Brasil, inserido no contexto da educação profissional, por meio do histórico de sua criação. Pretendeu-se conhecer o desenvolvimento e a evolução deste ensino, desde 1808 a 2015, diante das políticas públicas que nortearam a profissão e o ensino contábil, que hoje é reconhecido para registro pelo Conselho 
Federal de Contabilidade somente quando oferecido pelos cursos de bacharelado em Ciências Contábeis.

Esta pesquisa se contextualiza na linha de pesquisa Formação do Profissional Docente, Práticas Educativas e Gestão da Educação do Mestrado em Educação da Universidade do Vale do Sapucaí. Trata-se de um recorte de uma dissertação de mestrado que investiga a visão do aluno do Curso de Ciências Contábeis, em relação às exigências promovidas pelo Conselho Federal de Contabilidade para o exercício da profissão contábil.

Foi apresentada uma construção histórica, que tem como marco inicial a chegada da família real ao território brasileiro, em 1808. Dá-se nesse período o surgimento dos primeiros cursos superiores voltados para a preparação profissional, pois até aquele momento o ensino era conhecido por seu aspecto religioso. Nessa conjuntura histórica, surgem os primeiros ensaios do ensino comercial, pelas "aulas práticas" que mais tarde seriam chamadas por "aulas de comércio" (PELEIAS; BACCI, 2004).

A partir daí, o ensino comercial passou por várias mudanças provocadas pela conjuntura política e social brasileira, subsidiadas pelas legislações, o que será abordado detalhadamente nas seções deste artigo. Passou pela aprovação do primeiro Código Comercial Brasileiro em 1850, criação do Instituto Comercial do Rio de Janeiro em 1861, alteração nas matrizes curriculares e formas de admissão nos cursos comerciais até o reconhecimento dos diplomas da Academia de Comércio do Rio de Janeiro, em nível superior, em 1905.

Na década de 1930, com a criação do Ministério da Educação e Saúde Pública, o ensino comercial passa pela "Reforma do Ensino Comercial". Esse foi um Decreto, dentre vários outros publicados nesta época pelo ministro Francisco Campos (ROMERO, 2011). A reforma do ensino comercial regulamenta a profissão do contador, por meio do Decreto no 20.158, de 30 de junho de 1931 (BRASIL, 1931a), e ainda divide o ensino em três níveis: o propedêutico, o técnico e o superior, este último nomeado por Administração e Finanças (GOMES JUNIOR, 2013).

Foi somente no ano de 1945 que o curso superior passa a ser chamado de bacharelado em Ciências Contábeis e Atuariais e, em 1951, foi separado em dois cursos distintos, um bacharelado em Ciências Contábeis e outro bacharelado em Ciências Atuariais (PELEIAS et al., 2007). Ainda na década de 1940 foi criado o Conselho Federal de Contabilidade, por meio do Decreto no 9.295, de 27 de maio de 1946 (BRASIL, 1946), 
que se torna a entidade regulamentadora da profissão contábil. Assim, esse conselho fica responsável em tratar de todo assunto que diz respeito a matéria contábil.

Na Lei no 9.394, de 20 de dezembro de 1996, conhecida como Lei de Diretrizes e Bases da Educação Nacional (LDB) (BRASIL, 1996), foi concedida mais autonomia para as instituições de ensino elaborarem seus currículos, desde que fossem observadas as diretrizes gerais. Desde então, foram publicadas várias resoluções do Conselho Nacional de Educação (CNE) juntamente com a Câmara de Educação Superior (CES), com o objetivo de se tornarem referências para essas instituições de ensino superior (IES), de forma que pudessem elaborar e organizar seus projetos pedagógicos e matrizes curriculares, sendo a última Resolução vigente para o curso de Ciências Contábeis a Resolução CNE/CES no 10, de 16 de dezembro de 2004 (BRASIL, 2004a).

\section{O surgimento e a evolução do ensino contábil no Brasil}

A princípio, a formação acadêmica das classes mais favorecidas do Brasil, acontecia na metrópole portuguesa. No início do século XIX, o ensino que aqui era oferecido dedicava-se à catequização de indígenas, com formação clerical e formação da classe dominante. Esse ensino, oferecido com didática voltada para uma educação medieval latina, preparava os alunos que ingressariam na Universidade de Coimbra, em Portugal, que formava jovens nascidos no Brasil, nos cursos de Teologia, Direito Canônico, Direito Civil, Medicina e Filosofia, ocorrendo desta forma por três séculos (OLIVEN, 2002).

A chegada da Família Real trouxe para o Brasil um novo sentido à educação e à infraestrutura, com a abertura dos portos para as nações simpatizantes e a criação dos cursos de Medicina e Cirurgia, cursos esses ministrados no Hospital Militar. Esse fato fez com que o país alcançasse os setores da economia, da política e da agricultura, e que criasse cursos das variadas áreas do conhecimento. Até aquele momento o ensino conhecido era, predominantemente, o de caráter religioso. Esse novo ensino objetivou a formação dos servidores públicos, pelas Academias Militares em Medicina, Cirurgia, Matemática, Agricultura e outros (BOAVENTURA, 2009).

Com a instalação de Dom João VI na Bahia, logo recebeu solicitações da sociedade local para a abertura de universidades em território brasileiro. Porém, para atender esses pedidos o príncipe regente precisava de um significativo dispêndio financeiro. Desta forma, ao invés de universidade ele criou o Curso de Cirurgia, Anatomia e Obstetrícia na cidade de Salvador. Após a mudança de domicílio da Corte 
para a cidade do Rio de Janeiro, esses cursos e mais alguns também passaram a ser oferecidos nessa cidade (OLIVEN, 2002).

As primeiras faculdades em território brasileiro foram criadas para o ensino de Medicina, Direito e Politécnica e, geralmente, localizavam-se nas cidades de maior importância. Essas faculdades funcionavam de forma independente umas das outras (OLIVEN, 2002). De acordo com Peleias e Bacci (2004), também foi nesse período em torno de 1808, que o conhecimento das técnicas contábeis começou a ser discutido no Brasil.

Com a fundação da Real Junta de Comércio, Agricultura, Fábricas e Navegação passou a ser definido o uso do método das partidas dobradas, sistema que seria usado para a gestão dos bens do tesouro nacional, método esse que já era usado na Europa. De acordo com Sangster (2018),

O método das partidas dobradas, com o poder que o nível de conectividade entre todas as contas consigna ao sistema, representa um sistema fechado, axiomático e que serve necessidades específicas da empresa (conhecimento do lucro e do valor da riqueza), evidenciando claros benefícios em relação à contabilidade por partidas simples, designadamente por permitir que todas as entradas no sistema possam ser validadas pelas suas correspondentes contrapartidas (apud GONÇALVES, 2019, p.93).

Peleias e Bacci (2004, p. 41), ressaltam fatos ocorridos na época:

O ano de 1809 apresenta dois fatos relevantes:

- o primeiro, a promulgação do Alvará de 15 de julho, criando oficialmente o ensino de Contabilidade no país, por meio das aulas de comércio, intituladas 'aulas práticas';

- o segundo, a apresentação, pelo Visconde de Cairu, de um sistema de Direito Comercial, juntamente com a realização dos primeiros estudos sobre Economia Política no Brasil.

Diante disso, as Aulas de Comércio instaladas em 1810, ficaram aos cuidados de direção e de inspeção da Secretaria do Tribunal da Real Junta de Comércio, Agricultura, Fábricas e Navegação. Essas aulas tiveram como professor o Visconde de Cairu (GOMES JUNIOR, 2013).

Com a criação do Erário Régio e do Conselho de Fazenda, intensificou-se a demanda do ensino comercial no Brasil, cuja finalidade, era manter o controle das riquezas. Dessa forma foi organizada a Contabilidade do Erário Público e o método de escrituração. Além disso, passou a ser exigida dos "negociantes" a obrigação de manter os registros das atividades comerciais, por meio das escriturações mercantis. Esse 
documento deveria ser registrado e autenticado pela Junta Real do Comércio, e surgiu a demanda pelos profissionais conhecidos por guarda-livros e caixeiros (GOMES JUNIOR, 2013).

Com a instituição do Decreto no 456, de 6 de julho de 1846, foram regulamentadas as "aulas de comércio", que substituíram as "aulas práticas". Esse curso comercial era concluído em dois anos e, ao seu final, o aluno deveria ser aprovado em um exame com "[...] disciplinas de Matemática, Geografia, Economia Política, Direito Comercial, Prática das Principais Operações e Atos Comerciais" (PELEIAS; BACCI, 2004, p. 41).

A Lei no 556, de 25 de junho de 1850, publicou o primeiro Código Comercial Brasileiro, e estabeleceu que as empresas passassem a manter a escrituração contábil, que deveria seguir o método das partidas dobradas, e ao fim de cada exercício anual, deveria ser feito o encerramento e fechamento do Balanço Patrimonial dessas empresas. Assim, as empresas passaram a demonstrar suas informações contábeis em um formato com maior uniformidade, o que reforçou a necessidade de oferta do ensino comercial. Diante disto, no ano de 1856, foi criado o Instituto Comercial do Rio de Janeiro (PELEIAS; BACCI, 2004). O ensino comercial passaria a ser definido na próxima década pelo Decreto no 2.741, de 9 de fevereiro de 1861, que conforme Peleias et al. (2007, p.25), definiu:

[...] que os estudos do Instituto Comercial do Rio de Janeiro formariam um curso preparatório e outro profissional. Verifica-se, em seu artigo 1‥, que o curso profissional possuía quatro cadeiras, sendo a segunda de Escrituração Mercantil e Legislação de Fazenda. No artigo 10‥, consta que, para todas as aulas oferecidas no curso profissional, não seria exigida habilitação anterior, exceto para a de Escrituração Mercantil, cuja matrícula dependia de aprovação na cadeira de Aritmética Completa, a primeira oferecida.

Nessa mesma década, o ensino comercial sofreu algumas alterações, por meio do Decreto no 3.058, de 11 de março de 1863, que deliberou novos estatutos para o Instituto Comercial. 0 curso passou para 4 anos de duração, o que permitiu que jovens de 13 anos já pudessem se matricular, desde que estivessem aptos conforme os exames de gramática nacional e caligrafia (ALVES, 2014).

Esse currículo chama a atenção por sua extensa composição, em que constam três línguas estrangeiras, matemática e estatística. Entre 1879 e 1880, esse currículo foi reformulado, eliminadas algumas dessas disciplinas, de forma a reduzir o conteúdo e a duração do curso, que passou a ser de dois anos, conforme Decreto no 7.679, de 
28 de fevereiro de 1880, e Decreto no 7.538, de 15 de novembro de 1889 (SOARES et al., 2011). Esses decretos também modificaram a forma de admissão dos alunos no instituto, sendo exigidos no exame, conteúdos que antes eram abordados nas disciplinas lecionadas no curso, ou seja, os alunos já deveriam ter conhecimento desses conteúdos antes de iniciarem o curso (SOARES et al., 2011).

O Instituto de Comércio é extinto em 1902 e foi criada a Academia de Comércio do Rio de Janeiro, por meio do Decreto no 1.339, de 9 de janeiro de 1905, sendo considerada uma entidade de utilidade pública (MARRONI; RODRIGUES; PANOSSO, 2013), quando os diplomas foram oficialmente reconhecidos, e passam a ser oferecidos dois níveis de titulação; geral e superior.

As disposições instituídas no Decreto no 1.339/1905 trouxeram em seus artigos 2 ㅇ e 3으, uma extensão que dava o mesmo reconhecimento para os diplomas da Escola Prática de Comércio de São Paulo. Com o passar de alguns anos, esta entidade passou a se chamar Fundação Escola de Comércio Álvares Penteado e, pouco tempo depois já se transformou em uma referência em ensino comercial, ao mesmo nível da Academia de Comércio do Rio de Janeiro e da Academia de Comércio de Juiz de Fora, esta última já extinta na época, porém conferia os mesmos direitos aos que já tinham se formado nela (PELEIAS et al., 2007). Marroni, Rodrigues e Panosso (2013, p.7), referindo-se às disposições do Decreto no 17.329, de 28 de maio de 1926, enfatizam que esse Decreto criou:

[...] regulamento para os estabelecimentos de ensino técnico comercial que compreendia: o Curso Geral com duração de 4 anos (Propedêutico e Técnico) que dava direito ao diploma de contador e o Curso Superior de 3 anos que auferia o título de graduado em ciências econômicas. Porém, para obter o título de bacharel em Ciências Econômicas deveria, portanto, fazer além do curso geral de 4 anos, o curso superior de 3 anos.

Somente em 1920, próximo do primeiro centenário da Independência (1922), foi criada a primeira universidade brasileira, a Universidade do Rio de Janeiro, instituída pelo Decreto no 14.343, de 07 de setembro de 1920.

Após quase duas décadas do Decreto no 1.339/1905, o Senado Federal elaborou uma nova legislação que tratava a respeito do ensino comercial, o Decreto no 4.724-A, de 23 de agosto de 1923. Esse Decreto colocava a Academia Ciências Comerciais de Alagoas e outras academias em paralelo com a Academia de Comércio do Rio de Janeiro como forma de equiparar seus diplomas (GOMES JUNIOR, 2013). 
Entretanto, a fundamentação desta abertura e extensão de reconhecimento e oficialização para outras instituições escolares era a de que estas instituições deveriam seguir, rigorosamente, os programas desenvolvidos e estabelecidos nos cursos comerciais da Academia de Comércio do Rio de Janeiro, em virtude de ser esta uma escola de referência no Brasil, conforme expresso no Art. 20 do referido Decreto de 23 de agosto de 1923 (GOMES JUNIOR, 2013, p. 41).

Vale lembrar que Gomes Junior (2013, p. 44) ainda menciona que:

\begin{abstract}
Uma outra questão, não menos importante, era quando admitia-se que o curso comercial estava dirigido para uma formação específica voltada para o trabalho em atendimento às urgentes necessidades das empresas de profissionais com este tipo de formação e conhecimento. Havia um olhar imediatista e não de um horizonte de tempo maior com este ensino.
\end{abstract}

Esse imediatismo foi necessário, pois diante da crise mundial em torno de 1929, o Brasil era atingido por um recuo da economia interna. Essa queda se deu pela grande perda do mercado externo, principalmente na cafeicultura, um dos principais setores de exportação do país. Dessa forma, foi preciso dinamizar o mercado interno para substituir as importações, o que tornou-se benéfico para a formação profissional do país (GOMES JUNIOR, 2013).

\title{
Ensino superior de 1930 até 1946
}

No Governo provisório de Getúlio Vargas, iniciado em 1930, logo no próximo ano criou-se o Ministério da Educação e Saúde, ministrado por Francisco Campos, o qual instituiu vários decretos em seu exercício. Entre esses decretos, um promoveu uma reforma no ensino superior, que podia ser entendido por três partes, uma que tratou de aspectos gerais, outra mais específica que abordou a reorganização da Universidade do Rio de Janeiro, que seria vista como referência pelas outras instituições e a terceira, criou o Conselho Nacional de Educação (ROMERO, 2011).

Aprovado pelo Decreto no 19.851, de 11 de abril de 1931, o Estatuto das Universidades Brasileiras tinha como objetivo a organização do ensino superior com a regulamentação de um sistema universitário no país, para dar autonomia à direção das faculdades, através da reitoria, e trazer como requisito para a constituição de universidade, as exigências contidas no Art. 5을 do mencionado Decreto (ROMERO, 2011). 
No estado de São Paulo elaborava-se, nessa época, um projeto político para a criação de uma universidade exemplar, de alto nível acadêmico-científico, liderado por Fernando de Azevedo e com apoio do jornal "O Estado de S. Paulo", em conjunto com governo estadual da época. Dessa forma, foi criada em 1934, uma universidade pública estadual, desvinculada do controle do governo federal, a Universidade de São Paulo (USP). A USP representava grande mudança no que tange ao ensino superior da época, reunia ali faculdades tradicionais, o que originou a nova Faculdade de Filosofia, Ciências e Letras, com a contribuição de intelectuais estrangeiros, o que a colocou como referência nacional de pesquisa (OLIVEN, 2002). Paula (2002, p. 149), trata da importância dessa faculdade e da atuação dos pesquisadores estrangeiros:

[...] uma instituição dotada de organicidade e indispensável para se atingir a totalidade universitária. Esta faculdade é concebida pelos fundadores da USP como órgão fundamental para a constituição da nacionalidade. Georges Dumas, professor de sociologia da Sorbonne, se comprometeu a enviar, anualmente, ao Brasil, professores de várias universidades francesas, sendo o contato de Júlio de Mesquita Filho, na França, para a seleção dos professores que vieram compor o corpo docente da USP, em 1934.

Diante das legislações relacionadas ao ensino superior, o Ministério de Francisco Campos publicou o Decreto no 20.158/1931, que regulamentou a profissão de contador (BRASIL, 1931a). O ensino comercial nesse momento ficou dividido em três níveis: o propedêutico com duração de três anos, técnico com duração de dois anos, composto de secretário, de guarda-livros, de administrador-vendedor, de atuário e perito contador, e do superior de Administração e Finanças, conforme aponta Gomes Junior (2013). A regulamentação da profissão nesse Decreto exigia que o profissional contábil estivesse registrado na Superintendência do Ensino Comercial, conforme Art. 53 (BRASIL, 1931a, s.p.),

Fica instituído, na Superintendência do Ensino Comercial, o registo obrigatório dos certificados de auxiliar do comércio e dos diplomas de peritocontador, guarda-livros, administrador-vendedor, atuário, secretário e bacharel em ciências econômicas, expedidos pelos estabelecimentos dependentes da mesma Superintendência, e para os diplomas, títulos ou atestados de guarda-livros e contadores que se tenham habilitado para esse fim e na forma estabelecida por este decreto.

A partir desse momento começa a ser vista pela sociedade a importância do acompanhamento do profissional contábil na escrituração e elaboração dos livros comerciais. Passa a ser estabelecida pelo Decreto $\mathrm{n}$ - 21.033, de 8 de fevereiro de 1932, 
pelo Código Comercial e pela Lei de Falências vigente na época, a obrigatoriedade da assinatura, nesses livros, dos guarda-livros e contadores. Nesse Decreto também foram determinadas novas condições para o registro e habilitação dos profissionais contábeis (PELEIAS; BACCI, 2004).

Nesse contexto, o governo de Getúlio Vargas, no período conhecido por Estado Novo, tinha como meta econômica promover o avanço industrial no país. Para contribuir estrategicamente com o alcance dessa meta, foram criados vários órgãos com objetivo de sustentar certas áreas da economia, tais como o "Conselho Nacional do Petróleo, o Conselho Federal de Comércio Exterior e a Coordenação de Mobilização Econômica, esta instituída em 1942, com a entrada do Brasil na Segunda Guerra Mundial" (SILVA, 2015, p. 80-81).

Logo em seguida, o Decreto-Lei no 6.141, de 28 de dezembro de 1943, conhecida como Lei Orgânica do Ensino Comercial é estabelecido que este ensino passe a compor parte do ensino de segundo grau, com finalidade de formar profissionais aptos em funções comerciais e administrativas nos campos do poder público e privado (GOMES JUNIOR, 2013). Esse Decreto-Lei divide o ensino comercial em dois ciclos, um de formação básica e outro de caráter especial, composto por cinco cursos de formações específicas da área, sendo um deles o curso de contabilidade. O conjunto desses cursos é denominado como "cursos comerciais técnicos". Os cursos de formação comercial são estruturados pelo Decreto no 14.373, de 28 de dezembro de 1943 (MARRONI; RODRIGUES; PANOSO, 2013). Os cursos comerciais técnicos mencionados foram descritos no Art. 5o da Decreto-Lei no 6.141/1943 (BRASIL, 1943, p. s/n):

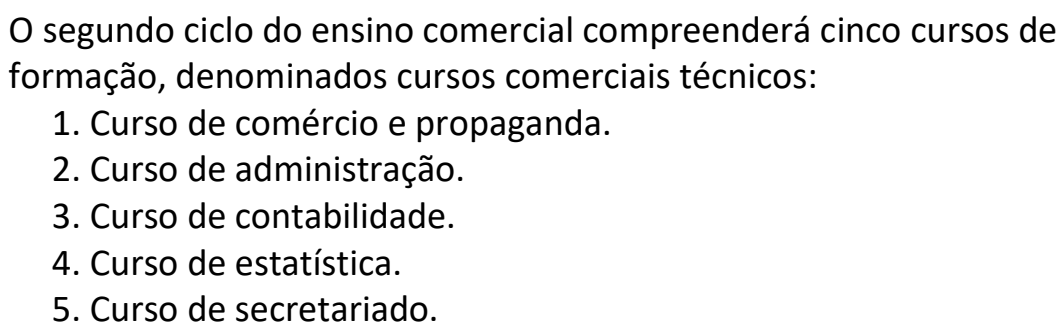

Na Secção V, do Decreto-Lei no 6.141/1943 ficou definido sobre os exames de suficiência, a aplicação de duas provas parciais, na forma escrita ou prática, em conformidade com a natureza da disciplina, com duas avaliações parciais, uma prova final oral ou prática feita na presença de uma banca examinadora.

Diante da conjuntura política do período pós-guerra, que trazia ideias indispensáveis para o desenvolvimento das forças produtivas internas do país, em 
dimensão tanto técnica quanto administrativa, o curso superior de Administração e Finanças passou ser reconhecido como Ciências Contábeis e Atuariais, por meio do Decreto-Lei no 7.988, de 22 de setembro de 1945. Dessa forma o título de bacharel em Ciências Contábeis e Atuariais foi concedido aos concluintes do curso. Também é definido por essa lei, o ensino de disciplinas com conteúdos mais específicos, conforme citado por Peleias et al. (2007, p. 27),

Em sua primeira edição, a grade curricular do curso tinha como disciplinas específicas: Contabilidade Geral, Organização e Contabilidade Industrial e Agrícola, Organização e Contabilidade Bancária, Organização e Contabilidade de Seguros, Contabilidade Pública e Revisões e Perícia Contábil.

Conforme Ricardino e Carvalho (2004), por meio do Decreto-Lei no 7.988/1945, foram introduzidas no ensino universitário as técnicas de auditoria e perícia contábil, oferecidas no quarto ano do curso superior dentre as demais disciplinas. Porém, nesse período, a denominação utilizada era "Revisões e Perícia Contábil", que trazia os conceitos e conteúdo da auditoria e da perícia contábil.

Diante das evoluções do ensino superior do curso de contábeis nessa década, por meio do Decreto-Lei no 8.191, de 20 de novembro de 1945, seria conferido o diploma de Técnico em Contabilidade aos concluintes do curso de guarda-livros, atuários e peritos-contadores formados nos cursos de nível médio. Os títulos então teriam apenas duas categorias: o técnico em contabilidade e o bacharel ou contador de nível superior (SILVA, 2015).

Desta maneira pode-se dizer que os profissionais com título de técnico em contabilidade e em guarda-livros, conforme mencionado no Decreto no 20.158/1931, eram aqueles formados no ensino técnico comercial, com atribuições "de escrituração contábil nos livros Diário e Razão, assinatura em balanço, balancetes e a organização de serviços de contabilidade em geral" (ARAUJO, 2007, p. 56). Já os Bacharéis, passam a ser chamados de Contadores, com todas as atribuições já exercidas pelo técnico em contabilidade e mais algumas atividades voltadas para área da perícia contábil, auditoria contábil e outras atividades com natureza técnica conferidas a eles por lei (ARAUJO, 2007).

Em 1946, diante da ascensão do ensino superior de contabilidade, o governo do estado de São Paulo criou a Faculdade de Ciências Econômicas e Administrativas, nas estruturas da USP, o que contribuiu para efetivação das pesquisas na área das Ciências Contábeis no Brasil. Nesse contexto o crescimento industrial em grandes cidades como 
São Paulo evidencia-se, cada vez mais a demanda desses profissionais o que exigia a capacitação de mão de obra nessa área do conhecimento (PELEIAS et al., 2007).

A profissão do contabilista tem como marco nesse ano de 1946, a criação do Conselho Federal de Contabilidade (CFC) e dos Conselhos Regionais de Contabilidade, por meio do Decreto-Lei no 9.295/1946. Nesse Decreto-Lei, no Art. 2o, ficou estabelecido que os conselhos de contabilidade teriam como competência fiscalizar a profissão do Contador e do Guarda-Livros. A criação do CFC, foi resultado de discussões do anteprojeto de Paulo Lyra Tavares apresentado em 1945, na I Convenção Nacional dos Contabilista, no Rio de Janeiro, e Tavares tornou-se o primeiro presidente desse Conselho (BUGARIM et al., 2013).

Com a criação dessa instituição a profissão então passa, nesse momento, a ser regulamentada por seu próprio conselho da classe profissional. Ao mesmo tempo, partia de um princípio básico, que tudo que se tratava de matéria contábil fazia parte da responsabilidade e atribuição do contabilista (BUGARIM et al., 2013).

Entre outras atribuições, ao CFC coube a competência de disciplinar as atividades dos Conselhos, com a finalidade de manter a unidade da estrutura federativa. Dessa forma, as atividades operacionais e administrativas dos Conselhos, em seu conjunto, passaram a ser realizadas de forma que não houvesse discrepância nos atos executados pelo CFC e CRCs, embora os Regionais mantivessem autonomia no que se refere à administração de seus serviços, gestão de recursos, regime de trabalho e relações empregatícias (BUGARIM et al., 2013, p.141-142).

Diante disso, com intuito de garantir a atuação profissional dentro dos padrões considerados como corretos, em 1950, ocorreu o primeiro ensaio de um Código de Ética Profissional. Esse documento foi aprovado no V Congresso Brasileiro de Contabilidade, sediado na cidade de Belo Horizonte, que teve os pontos definidos nesse código como principal pauta. O código de ética abordava um conjunto de normas relativas à ética profissional, que deveriam ser seguidas pelos contabilistas. Embora esse documento não tenha sido considerado pelo CFC, como de caráter normativo, demonstrava a preocupação dos conselhos de contabilidade em assegurar que a atuação do contabilista fosse oferecida dentro dos padrões éticos (BUGARIM et al., 2013).

\section{O Ensino de Contabilidade e o Conselho de Contabilidade (1950- 2015)}

A publicação da Lei no 1.401, de 31 de julho de 1951, trouxe mudanças para o ensino superior de Ciências Contábeis e Atuariais, com o desmembramento em dois 
cursos: um denominado por Ciências Contábeis e outro por Ciências Atuariais. Desta maneira, esses cursos tomam direções com mais delimitações das áreas de formação, e o Art. 4 을 dessa Lei estabeleceu a possibilidade da redução do prazo de integralização desses cursos para 3 anos (PELEIAS et al., 2007).

No governo de Juscelino Kubitschek, a partir de 1955, foi proposto no Plano de Metas, o desenvolvimento do segundo setor, resultou em altas taxas de crescimento do PIB. Com essas mudanças, houve aumento da demanda por profissionais da área contábil, e em decorrência a necessidade de adaptação no perfil desses profissionais, e ainda, nos currículos dos cursos de graduação dessa área (PELEIAS et al., 2007).

Com a Lei no 4.024, de 20 de dezembro de 1961, o Conselho Federal de Educação (CFE) ${ }^{4}$ fixa currículos mínimos e tempo de duração para os cursos superiores de formação de profissões regulamentadas, que foi o caso do curso de Ciências Contábeis. Esse Conselho publicou o Parecer no 397/1962, que divide o ensino de contábeis em um ciclo de formação básica e outro profissional composto por disciplinas de conteúdo específicos da contabilidade. Conforme relembrado por Ricardino e Carvalho (2004, p. 29):

\footnotetext{
A primeira reestruturação de porte no conteúdo programático dos cursos de Ciências Contábeis deu-se em 1963, através da Resolução S/N, de 08 de fevereiro de 1963. A Resolução tinha por objetivo fixar o currículo mínimo e a duração dos cursos de Ciências Atuariais, Ciências Contábeis e Ciências Econômicas. Dentre as disciplinas que integravam o 'Ciclo de Formação Profissional' incluía-se a 'Auditoria e Análise de Balanços'.
}

Ainda nessa década, o mercado de capitais passou a ser organizado no Brasil, pela Lei no 4.728, de 14 de julho de 1965, criada para disciplinar, fortalecer e estabelecer normas nesse novo modelo de mercado. Dentre as normas trazidas por essa lei, a exigência de padrões de conduta das empresas que integravam esse mercado, foi uma das preocupações abordadas, com o objetivo de conquistar a confiança do público investidor. Diante disso, foi atribuído ao Conselho Monetário Nacional expedir normas, que deveriam ser seguidas pelas empresas que compunham o mercado de capitais e pelos profissionais que nele atuariam, com citação pela

\footnotetext{
${ }^{4}$ Conforme o Art. 10 do Decreto no 19.850, de 1931 "Fica instituído o Conselho Nacional de Educação, que será o órgão consultivo do ministro da Educação e Saúde Pública nos assumptos relativos ao ensino." (BRASIL, 1931c, s.p.). Na Lei no 4.024/1961, conforme Art. 7으, o Conselho passa a ser chamado de Conselho Federal da Educação: "Ao Ministério da Educação e Cultura incumbe velar pela observância das leis do ensino e pelo cumprimento das decisões do Conselho Federal de Educação." (BRASIL, 1961, s.p.).
} 
primeira vez a figura do Auditor Independente, que deveria seguir tais normas e obter o seu registro de habilitação no Banco Central (RICARDINO; CARVALHO, 2004).

Na década de 1970, diante de alguns debates sobre a profissão contábil é elaborado o Código de Ética Profissional do Contabilista, de caráter normativo, publicado pelo CFC, por meio da Resolução no 290, de 04 de setembro de 1970. Além disso, no que tange à evolução do ensino contábil no Brasil nessa década, a Faculdade de Economia, Administração e Contabilidade da Universidade de São Paulo (FEA/USP) passa a ofertar a primeira pós-graduação Stricto Sensu em Controladoria e Contabilidade (PELEIAS et al., 2007).

No ano de 1976 foi criada a Comissão de Valores Mobiliários (CVM), que, de certa, forma fortalece a figura da auditoria contábil. Foi criada para registrar e fiscalizar o mercado de valores mobiliários, mas também como atribuição deveria registrar e fiscalizar os Auditores Independentes, capacitados a auditar as companhias de capital (RICARDINO; CARVALHO, 2004). Nesse mesmo ano, a Lei no 6.404, de 15 de dezembro de 1976, conhecida por Lei das Sociedades por Ações, estabeleceu que as empresas dessa natureza apresentassem pareceres de auditoria independente de suas demonstrações contábeis, e ainda estipulou normas contábeis, impostas para as escriturações dessas companhias.

A Resolução no 529, de 23 de outubro de 1981, dispôs "sobre as Normas Brasileiras de Contabilidade" que deveriam ser elaboradas por uma "Comissão de Consultores" indicados pelo próprio conselho, e serviriam como orientação para os profissionais das mais diversas áreas da profissão contábil. Essas normas deveriam ser organizadas em duas classificações: as técnicas e as profissionais. As técnicas abordariam conceitos que fixassem regras ou critérios da contabilidade, identificadas pela sigla NBC-T e as profissionais estabeleceriam regras de ordem profissional, identificadas pela sigla NBC-P (BRASIL, 1981a).

A Resolução no 530, de 23 de outubro de 1981, aprovou a norma técnica, NBC - T 1 com 16 princípios fundamentais de contabilidade, que dariam as demonstrações contábeis maior uniformidade em sua elaboração (BRASIL, 1981b). Para Peleias et al. (2007, p. 27), "os anos 1980 foram considerados a Década Perdida. Não houve, no período mencionado, mudanças no ensino superior de Contabilidade por comando legal". Esse autor delineia esse período nos seguintes termos:

Em 1985, o controle político volta aos civis. A partir de 1989 retorna a eleição direta para Presidente da República e, em 1994, inicia-se a estabilidade inflacionária, com o Plano Real. É nesse cenário que voltam a ocorrer 
mudanças no ensino superior de Contabilidade, em especial a partir da década de 1990 (PELEIAS et al., 2007, p. 28).

No contexto de mudanças, o curso de Ciências Contábeis, por meio da Resolução do CFE de no 03, de 03 de outubro de 1992, teve fixada uma carga horária mínima de 2700 horas de aulas, oferecidas pelas instituições, com duração de no mínimo quatro anos para os períodos diurnos, cinco anos para os períodos noturnos e no máximo sete anos de integralização do curso. Essa Resolução também exige a definição de conteúdos mínimos que deveriam ser lecionados e estipula normas para que as instituições elaborem os currículos de acordo com o perfil do profissional que seria formado (HOFER; PELEIAS; WEFFORT, 2005).

A promulgação da Lei no 9.394/96 estabeleceu as Diretrizes e Bases da Educação Nacional e introduziu novas alterações no ensino superior, tais como: a qualificação docente, a produção intelectual, os docentes em regime de tempo integral e o perfil profissional ligado à formação da cultura regional e nacional (HOFER; PELEIAS; WEFFORT, 2005, p. 120).

A Lei no 9.394/1996, em seu Capítulo IV, sobre a Educação Superior, no inciso III, do Art. 53, trata da autonomia das instituições de ensino em elaborar seus currículos, desde que sejam observadas as diretrizes gerais (BRASIL, 1996). Diante disso, logo no próximo ano como forma de melhor esclarecer, o CNE publica o Parecer CNE no 776, de dezembro de 1997, que "orienta para as diretrizes curriculares dos cursos de graduação" (BRASIL, 1997a, p.1). Nesse mesmo ano, o Ministério da Educação (MEC) publicou o Edital no 04/97, por intermédio da Secretaria de Educação Superior (SESU), o qual tornou público e convocou as IES a apresentarem propostas para as novas Diretrizes Curriculares dos cursos em nível superior e as Comissões de Especialistas da Sesu/MEC que elaborariam essas diretrizes. Esse Edital tinha como principal objetivo colocar em prática o Art. 53, da LDB, conforme abaixo na íntegra do texto:

As Diretrizes Curriculares têm por objetivo servir de referência para as IES na organização de seus programas de formação, permitindo uma flexibilidade na construção dos currículos plenos e privilegiando a indicação de áreas do conhecimento a serem consideradas, ao invés de estabelecer disciplinas e cargas horárias definidas. As Diretrizes Curriculares devem contemplar ainda a denominação de diferentes formações e habilitações para cada área do conhecimento, explicitando os objetivos e demandas existentes na sociedade (BRASIL, 1997b, p. 1). 
O Parecer do CES/CNE no 146, de 3 de abril de 2002, foi o ponto de partida para a publicação de outros editais no que diz respeito aos assuntos das Diretrizes Curriculares Nacionais, em especial para o Curso de Ciências Contábeis (PELEIAS et al., 2007). Esse Parecer trata sobre as "Diretrizes específicas por curso relatado", dos cursos de graduação em "Direito, Ciências Econômicas, Administração, Ciências Contábeis, Turismo, Hotelaria, Secretariado Executivo, Música, Dança, Teatro e Design" (BRASIL, 2002, p.1). Conforme subtítulo 3.2.4 "Curso de Graduação em Ciências Contábeis" esse documento traz a seguinte orientação:

\begin{abstract}
Os cursos de graduação em Ciências Contábeis deverão contemplar, em seus projetos pedagógicos e em sua organização curricular, conteúdos que atendam aos seguintes eixos interligados de formação: I - Conteúdos de Formação Básica: estudos relacionados com outras áreas do conhecimento, sobretudo Administração, Economia, Direito, Métodos Quantitativos, Matemática e Estatística; II - Conteúdos de Formação Profissional: estudos específicos atinentes às Teorias da Contabilidade, além de suas relações com a Atuária, e da Auditoria, da Controladoria e suas aplicações peculiares ao setor público e privado; III - Conteúdos de Formação Teórico-Prática: Estágio Curricular Supervisionado, Atividades Complementares, Estudos Independentes, Conteúdos Optativos, Prática em Laboratório de Informática utilizando softwares atualizados para Contabilidade (BRASIL, 2002, p.17).
\end{abstract}

Esse Parecer foi revogado em 2003 pelo Parecer CES/CNE no 67, de 11 de março de 2003, que buscou reunir em um só documento, "[...] todas as referências normativas existentes na Câmara relacionadas com a concepção e a conceituação dos Currículos Mínimos Profissionalizantes [...]" (BRASIL, 2003a, p.1).

Ainda em 2003 foi aprovado o Parecer CNE/CES no 289 que trata sobre as Diretrizes Curriculares Nacionais da Graduação de Ciências Contábeis, seguidas pelas IES, na elaboração de seus projetos pedagógicos. Nesse Parecer, o CNE acolheu contribuições encaminhadas pelo Conselho Federal de Contabilidade, consideradas significativas para a formação profissional contábil:

Por esta razão, foi acolhida parte significativa das novas contribuições encaminhadas especialmente pelo Conselho Federal de Contabilidade, notadamente no que se refere à duração do curso, necessária à execução qualitativa do projeto pedagógico do curso, à inserção da atividade atuarial no domínio contábil, às responsabilidades específicas dos contadores, sobretudo em apurações, auditorias, perícias, arbitragens e quantificações de informações financeiras, patrimoniais e governamentais e suas implicações com o cenário econômico e financeiro, nacional e internacional, observadas as normas e padrões internacionais de contabilidade. Atenta ainda o Conselho Federal de Contabilidade para que a reorganização 
curricular do curso de Ciências Contábeis assegure o domínio de inovações tecnológicas em organizações de pequeno ou grande porte, públicas ou privadas, devendo o contador revelar capacidade crítico-analítica para avaliar as implicações organizacionais com o advento da tecnologia da informação (BRASIL, 2003b, p.3).

Conforme Peleias et al. (2007), a Resolução do CNE/CES de no 6, de 10 de março de 2004, legitimou o Parecer no 289/2003, porém, a pedido do Instituto Brasileiro de Atuaria (IBA), parte do documento que menciona que o curso de Ciências Contábeis, deveria abranger "a inserção da atividade atuarial no domínio contábil" (BRASIL, 2004b, p.3). O IBA ainda se posiciona que o curso de contábeis não se confunde com o curso atuarial, já que possuem fundamentos distintos. Isso, levou o CNE e CES a publicar a Resolução CNE/CES no 10/2004, que em seu Art. 2oㅡ, estabeleceu a organização curricular dos cursos de bacharelado de Ciências Contábeis pelas IES, por meio dos projetos pedagógicos desse curso. Niyama et al. (2008, p. 105) menciona que essa Resolução veio estabelecer que seja contemplado um perfil do graduado em Ciências Contábeis que venha "revelar dentre outras, capacidades de enquadramento e atuação nos diversos modelos organizacionais, tanto nacionais quanto influenciados por modelos e normas internacionais". Assim, esse curso deve capacitar os futuros contabilistas para compreenderem tanto questões nacionais quanto internacionais.

No Art. 3 da Resolução CNE/CES no 10/2004 são tratadas as condições para a capacitação do futuro profissional contábil nos seguintes termos:

I - compreender as questões científicas, técnicas, sociais, econômicas e financeiras, em âmbito nacional e internacional e nos diferentes modelos de organização;

II - apresentar pleno domínio das responsabilidades funcionais envolvendo apurações, auditorias, perícias, arbitragens, noções de atividades atuariais e de quantificações de informações financeiras, patrimoniais e governamentais, com a plena utilização de inovações tecnológicas;

III - revelar capacidade crítico-analítica de avaliação, quanto às implicações organizacionais com o advento da tecnologia da informação (BRASIL, 2004a, s.p.).

No Art. 5을 dessa Resolução são destacados os conteúdos que deveriam ser observados nos projetos pedagógicos e currículos dos cursos da graduação de Ciências Contábeis. Esses conteúdos deveriam ter abrangência do conhecimento das questões econômicas nacionais e internacionais, de forma que se proporcione ao egresso conhecimento da harmonização das normas e padrões internacionais, elencadas pela Organização Mundial do Comércio e das questões particulares de órgãos 
governamentais. Esses conteúdos foram divididos nos grupos de Formação Básica, Formação Profissional e Formação Teórico-Prática (BRASIL, 2004a).

Em 2008, a Lei no 9.394/96, foi alterada pela Lei no 11.741, de 16 de julho de 2008 (BRASIL, 2008), para redimensionamento, institucionalização e integração das "ações da educação profissional técnica de nível médio, da educação de jovens e adultos e da educação profissional e tecnológica". Em seu Art. 39 consta que "A educação profissional e tecnológica, no cumprimento dos objetivos da educação nacional, integra-se aos diferentes níveis e modalidades de educação e às dimensões do trabalho, da ciência e da tecnologia" (BRASIL, 1996). No § 10 do Art. 39 ficou estabelecido que "os cursos de educação profissional e tecnológica poderão ser organizados por eixos tecnológicos, possibilitando a construção de diferentes itinerários formativos, observadas as normas do respectivo sistema e nível de ensino. (Incluído pela Lei no 11.741, de 2008)". E ainda no § 2ㅇ desse Art. 39, estabelece que a educação profissional e tecnológica abrangerá os cursos:

I - de formação inicial e continuada ou qualificação profissional; (Incluído pela Lei no 11.741 , de 2008)

II - de educação profissional técnica de nível médio; (Incluído pela Lei no 11.741, de 2008)

III - de educação profissional tecnológica de graduação e pós-graduação. (Incluído pela Lei no 11.741, de 2008) (BRASIL, 1996, s.p.).

Desta forma, os cursos de formação profissional passaram a abordar conteúdos com maior harmonização em seus currículos, o que favoreceu ao aluno obter uma formação mais uniformizada.

No ano de 2010, a Lei no 12.249 , de 11 de junho de 2010, alterou Decreto-Lei no 9.295/1946, que especificamente no Art. 12 passou a ter a seguinte redação:

Os profissionais a que se refere este Decreto-Lei somente poderão exercer a profissão após a regular conclusão do curso de Bacharelado em Ciências Contábeis, reconhecido pelo Ministério da Educação, aprovação em Exame de Suficiência e registro no Conselho Regional de Contabilidade a que estiverem sujeitos (BRASIL, 1946, s.p.).

No $\S 10$ desse Art. 12 consta que "o exercício da profissão, sem o registro a que alude êste artigo, será considerado como infração do presente Decreto-lei". E no § 2은 estabelece que "os técnicos em contabilidade já registrados em Conselho Regional de Contabilidade e os que venham a fazê-lo até 1ㅇ de junho de 2015 têm assegurado o seu direito ao exercício da profissão" (BRASIL, 1946, s.p.). 


\section{Considerações finais}

O ensino contábil surge no Brasil para atender à demanda de profissionais, para trabalharem nas entidades como o Erário Régio e o Conselho da Fazenda, criadas para cuidar e controlar as riquezas da nação para o governo da época, o que exigia a formação de profissionais com conhecimento seguro da tarefa que iriam exercer. Isto tornou necessária a formação de profissionais com esse conhecimento.

Esse controle passou a ser estendido aos comerciantes que mantivessem a escrituração contábil de seus negócios, o que aumentou a demanda dos serviços contábeis. Dessa maneira, o ensino contábil passou a ser realizado com maior aprofundamento e rigor, devido à responsabilidade que o profissional dessa área teria na elaboração das informações contábeis. Observou-se que no ano de 1846 já era exigida dos alunos a aprovação em exame final com conteúdos que abordavam disciplinas de Direto Comercial, Práticas das Principais Operações e Atos Comerciais.

Notou-se que desde o Século XIX, o ensino contábil foi sendo adaptado, por várias vezes, de acordo com exigências que o mercado atribuía a este profissional. $\mathrm{E}$ foi no início do Século $X X$, que esse ensino tornou-se reconhecido no Brasil, por meio do Decreto no 4.724-A/1923, em nível de ensino superior em algumas instituições, e ainda passaram a ser equiparados diplomas de outras instituições com a Academia de Comércio do Rio de Janeiro, considerada uma referência para as demais instituições.

A criação do Conselho Federal de Contabilidade se deu no ano de 1946, e veio fiscalizar, regulamentar e fixar as atribuições e responsabilidades da profissão contábil. Desta forma, o governo passa a cuidar das questões do ensino dessa profissão e não mais do exercício e fiscalização. Daí por diante, pode-se observar que foram instituídas, pelo governo, várias legislações com intuito de nortear o ensino e, o Conselho Federal de Contabilidade, as legislações que norteiam a prática e conduta do profissional.

Este estudo contribui, para que se possa ter maior clareza de como esse ensino desenvolveu e evoluiu no Brasil e mostra os principais marcos que influenciaram a profissão e o ensino contábil, que, por sua vez, foi se adaptando de acordo com as necessidades demandadas pelo mercado econômico e político, vigente em cada época. Diante dessas considerações, esperamos que este artigo, possa servir como material de pesquisa, sobre a evolução da educação profissional e do ensino comercial no Brasil.

Finalmente, pode-se questionar a extinção em 2015 do registro profissional em nível Técnico em Contabilidade, observado ao longo da pesquisa, que aqueles que 
concluírem o curso técnico em contabilidade não terão mais direito ao registro no Conselho. Na realidade, a profissão de Técnico em Contabilidade foi extinta, repito. Obviamente respeitados os direitos adquiridos, tal decisão deixará uma lacuna nos serviços de contabilidade, analogamente, também seria inconcebível para as áreas das engenharias, onde há o técnico em edificações, eletrotécnico, técnico agropecuário etc. Na saúde, em enfermagem, são os técnicos em enfermagem que operacionalizam as enfermarias, unidades de terapias intensivas. Sem mencionar que em tantas outras áreas existe o concurso do citado profissional de nível técnico. Por fim, acredita-se que toda atividade técnica tem sua representatividade e valor, sua responsabilidade e contribuição para as atividades fins da profissão, sendo uma base importante de conhecimento para dar suporte, respaldo e qualidade para a entrega serviço.

\section{Referências}

ALVES, D. Alinhamento entre os conteúdos de contabilidade nos Cursos de Ciências Contábeis no Brasil com os pronunciamentos técnicos da CPC harmonizados com as normas internacionais de contabilidade. 2014. 87f. Dissertação (Mestrado em Ciências Contábeis) - Universidade do Rio dos Sinos, São Leopoldo, 2014. Disponível em:

http://www.repositorio.jesuita.org.br/bitstream/handle/UNISINOS/3870/Diego\%20S aldo\%20Alves.pdf? sequence=1\&isAllowed=y. Acesso em: 20 set. 2018.

ARAUJO, K. S. Educação continuada na profissão contábil: um estudo de caso no CRC/SE. 2007. 149f. Dissertação (Mestrado em Educação) - Universidade Federal de Sergipe, São Cristóvão, SE, 2007. Disponível em: https://ri.ufs.br/handle/riufs/4624. Acesso em: 16 dez. 2017.

BOAVENTURA, E. M. A educação brasileira no período joanino. Salvador: EDUFBA, 2009. e-book. Disponível em: http://books.scielo.org/id/4r/pdf/boaventura9788523208936-08.pdf. Acesso em: 01 maio. 2018.

BRASIL. Alvará de 23 de agosto de 1808. Crêa o Tribunal da Real Junta do Commercio, Agricultura, Fabricas e Navegação. Coleção de Leis do Império do Brasil, Rio de Janeiro, 1808.

BRASIL. Conselho Nacional de Educação. Câmara De Educação Superior. Resolução no 6, de 10 de março de 2004. Institui as Diretrizes Curriculares Nacionais do Curso de Graduação em Ciências Contábeis, bacharelado, e dá outras providências. Brasília: Câmara de Educação Superior, 2004. 2004b. 
BRASIL. Conselho Nacional de Educação. Câmara De Educação Superior. Resolução CNE/CES no 10, de 16 de dezembro de 2004. Institui as Diretrizes Curriculares Nacionais para o Curso de Graduação em Ciências Contábeis, bacharelado, e dá outras providências. Diário Oficial da União, Brasília, 28 dezembro de 2004. 2004a. Disponível em: http://portal.mec.gov.br/cne/arquivos/pdf/rces010_04.pdf. Acesso em: 16 dez. 2017.

BRASIL. Decreto no 1.339, de 9 de janeiro de 1905. Declara instituição de utilidade publica a Academia de Commercio do Rio de Janeiro, reconhece os diplomas por ella conferidos, como de caracter official; e dá outras providencias. Diário Oficial da União, Rio de Janeiro, 11 de janeiro de 1943.

BRASIL. Lei no 12.249, de 11 de junho de 2010. Institui o Regime Especial de Incentivos para o Desenvolvimento de Infraestrutura da Indústria Petrolífera [...].

Diário Oficial da União, Brasília, 14 de junho de 2010. Disponível em: http://www.planalto.gov.br/ccivil_03/_Ato2007-2010/2010/Lei/L12249.htm. Acesso em: 16 dez. 2017.

BRASIL. Decreto no 2.741, de 9 de fevereiro de 1861. Dá nova organisação ao Instituto Commercial do Rio de Janeiro. Disponível em:

https://www2.camara.leg.br/legin/fed/decret/1824-1899/decreto-2741-9-fevereiro1861-556068-publicacaooriginal-75720-pe.html. Acesso em: 16 dez. 2017.

BRASIL. Decreto no 14.343, de 7 de setembro de 1920. Institue a Universidade do Rio de Janeiro. Diário Oficial da União, Rio de Janeiro, 10 de setembro de 1920.

BRASIL. Decreto no 14.373, de 28 de dezembro de 1943. Regulamento da estrutura dos cursos de formação do ensino comercial. República, Rio de Janeiro, 31 de dezembro de 1943. 1943b.

BRASIL. Decreto no 17.329, de 28 de maio de 1926. Approva, o regulamento para os estabelecimentos de ensino technico commercial reconhecidos officialmente pelo Governo Federal. Diário Oficial da União, Rio de Janeiro, 10 de novembro de 1926.

BRASIL. Decreto no 19.850, de 11 de abril de 1931. Crêa o Conselho Nacional de Educação. Diário Oficial da União, Rio de Janeiro, 15 de abril de 1931. 1931c. Disponível em: https://www2.camara.leg.br/legin/fed/decret/1930-1939/decreto19850-11-abril-1931-515692-publicacaooriginal-1-pe.html. Acesso em: 16 dez. 2017.

BRASIL. Decreto no 19.851, de 11 de abril de 1931. Dispõe que o ensino superior no Brasil obedecerá, de preferencia, ao systema universitario, podendo ainda ser ministrado em institutos isolados, e que a organização technica e administrativa das universidades é instituida no presente Decreto, regendo-se os institutos isolados pelos respectivos regulamentos, observados os dispositivos do seguinte Estatuto das 
Universidades Brasileiras. Diário Oficial da União, Rio de Janeiro, 15 de abril de 1931. 1931b. Disponível em: https://www2.camara.leg.br/legin/fed/decret/19301939/decreto-19851-11-abril-1931-505837-publicacaooriginal-1-pe.html. Acesso em: 16 dez. 2017.

BRASIL. Decreto no 20.158, de 30 de junho de 1931. Organiza o ensino comercial, regulamenta a profissão de contador e dá outras providências. Diário Oficial da União, Rio de Janeiro, 13 de fevereiro de 1932. 1931a. Disponível em: https://www2.camara.leg.br/legin/fed/decret/1930-1939/decreto-20158-30-junho1931-536778-republicacao-81246-pe.html. Acesso em: 16 dez. 2017.

BRASIL. Decreto no 21.033, de 8 de fevereiro de 1932. Estabelece novas condições para o registo de contadores e guarda-livros, e da outras providências. Coleção de Leis do Império do Brasil, Rio de Janeiro, 1932.

BRASIL. Decreto no 3.058, de 11 de março de 1863. Dá novos Estatutos ao Instituto Commercial do Rio de Janeiro. Coleção de Leis do Império do Brasil, Rio de Janeiro,1863.

BRASIL. Decreto no 4.724-A, de 23 de agosto de 1923. Equipara os diplomas da Academia de Sciencias Commerciaes de Alagôas e de outras instituições, aos da Academia de Commercio do Rio de Janeiro e dá outras providencias. Coleção de Leis do Império do Brasil, Rio de Janeiro, 1923.

BRASIL. Decreto no 456, de 6 de julho de 1846. Manda executar o regulamento da Aula do commercio da Cidade do Rio de Janeiro. Coleção de Leis do Império do Brasil, Rio de Janeiro, 1846.

BRASIL. Decreto-lei 6.141, de 28 de dezembro de 1943. Lei orgânica do Ensino Comercial. Diário Oficial da União, Rio de Janeiro, 31 de dezembro de 1943. 1943a. Disponível em: https://www2.camara.leg.br/legin/fed/declei/1940-1949/decreto-lei6141-28-dezembro-1943-416183-publicacaooriginal-1-pe.html. Acesso em: 16 dez. 2017.

BRASIL. Decreto-lei no 7.988, de 22 de setembro de 1945. Dispõe sobre o ensino superior de ciências econômicas e de ciências contábeis e atuariais. Diário Oficial da União, Rio de Janeiro, 26 de setembro de 1945. 1945a.

BRASIL. Decreto-lei no 8.191, de 20 de novembro de 1945. Disposições relativas ao curso comercial básico e a seus atuais alunos da terceira e quarta séries. Diário Oficial da União, Rio de Janeiro, 27 de novembro de 1945. 1945b.

BRASIL. Decreto-lei no 9.295, de 27 de maio de 1946. Cria o Conselho Federal de Contabilidade, define as atribuições do Contador e do Guarda-livros, e dá outras providências. Diário Oficial da União, Rio de Janeiro, 29 de maio de 1946. 
BRASIL. Lei no 6.404, de 15 de dezembro de 1976. Dispõe sobre as Sociedades por Ações. Diário Oficial da União, Brasília,17 de dezembro de 1976. Disponível em: http://www.planalto.gov.br/ccivil_03/leis/I6404consol.htm. Acesso em: 16 out. 2018.

BRASIL. Lei no 1.401, de 31 de julho de 1951. Inclui, no curso de ciências econômicas, a cadeira de Historia Econômica Geral e do Brasil, e desdobra o curso de ciências contábeis e atuariais. Diário Oficial da União, Rio de Janeiro, 4 de agosto de 1951.

BRASIL. Lei $n$ ㅇ 11.741, de 16 de julho de 2008. Altera dispositivos da Lei $n=9.394$, de 20 de dezembro de 1996, que estabelece as diretrizes e bases da educação nacional, para redimensionar, institucionalizar e integrar as ações da educação profissional técnica de nível médio, da educação de jovens e adultos e da educação profissional e tecnológica. Diário Oficial da União, Brasília, 17 de julho de 2008. Disponível em: http://www.planalto.gov.br/ccivil_03/_Ato2007-2010/2008/Lei/L11741.htm. Acesso em: 16 dez. 2017.

BRASIL. Lei no 4.024, de 20 de dezembro de 1961. Fixa as Diretrizes e Bases da Educação Nacional. Diário Oficial da União, Brasília, DF, 27 de dezembro de 1961. Disponível em: https://www2.camara.leg.br/legin/fed/lei/1960-1969/lei-4024-20dezembro-1961-353722-normaatualizada-pl.pdf. Acesso em: 01 maio. 2018.

BRASIL. Lei no 4.728, de 14 de julho de 1965. Disciplina o mercado de capitais e estabelece medidas para o seu desenvolvimento. Diário Oficial da União, Brasília, 16 de julho de 1965.

BRASIL. Lei no 556, de 25 de junho de 1850. Código Comercial. Secretaria d'Estado dos Negocios da Justiça, 1850.

BRASIL. Lei no 9.394, de 20 de dezembro de 1996. Estabelece as Diretrizes e Bases da Educação Nacional. 1996. Diário Oficial da União, Brasília, 23 de dezembro de 1996. Disponível em: http://www.planalto.gov.br/ccivil_03/leis/19394.htm. Acesso em: 16 dez. 2017.

BRASIL. Ministério da Educação e do Deporto. Conselho Nacional da Educação. Secretária de Educação Superior. Edital no 04, de 10 de dezembro de 1997. Torna público e convoca as instituições de ensino superior a apresentar propostas para as novas diretrizes curriculares dos cursos superiores, que serão elaboradas pelas comissões de especialistas da SESu/MEC. Brasília: SESu/MEC, 1997. 1997b. Disponível em: http://abepsi.org.br/wp-content/uploads/2011/07/1997-editaln041997.pdf. Acesso em: 16 dez. 2017.

BRASIL. Ministério da Educação e do Deporto. Conselho Nacional da Educação. Câmara de Educação Superior. Parecer no 146, de 3 de abril de 2002. Diretrizes Curriculares Nacionais dos cursos de graduação em Direito, Ciências Econômicas, 
Administração, Ciências Contábeis, Turismo, Hotelaria, Secretariado Executivo, Música, Dança, Teatro e Design. Brasília: SESu/MEC, 2002.

BRASIL. Ministério da Educação e do Deporto. Conselho Nacional da Educação. Câmara de Educação Superior. Parecer no 67, de 11 de março de 2003. Referencial para as Diretrizes Curriculares Nacionais - DCN dos Cursos de Graduação. Diário Oficial da União, Brasília, 13 de março de 2003. 2003a. Disponível em: http://portal.mec.gov.br/cne/arquivos/pdf/CES0067.pdf. Acesso em: 16 dez. 2017.

BRASIL. Ministério da Educação e do Deporto. Conselho Nacional da Educação. Câmara de Educação Superior. Parecer no 289, de 6 de novembro de 2003. Diretrizes Curriculares Nacionais do Curso de Graduação em Ciências Contábeis. Diário Oficial da União, Brasília, 12 fevereiro de 2004. 2003b. Disponível em: http://portal.mec.gov.br/cne/arquivos/pdf/2003/pces289_03.pdf. Acesso em: 16 dez. 2017.

BRASIL. Ministério da Educação. Parecer CFE no 397/62. Divide os cursos de Ciências Econômicas, Ciências Contábeis e Ciências Atuariais nos ciclos básico e de formação profissional.

BRASIL. Parecer CNE no 776 de 1997. Orienta para as diretrizes curriculares dos cursos de graduação. Brasília: Câmara de Educação Superior, 1997. 1997a. Disponível em:

http://portal.mec.gov.br/setec/arquivos/pdf_legislacao/superior/legisla_superior_pa recer77697.pdf. Acesso em: 16 dez. 2017.

BRASIL. Resolução CFE no 3, de 3 de outubro de 1992. Fixa os mínimos de conteúdo e duração do curso de graduação em Ciências Contábeis.

BRASIL. Resolução no 290, de 4 de setembro de 1970. Aprova o Código de Ética Profissional do Contabilista.

BUGARIM, M. C. C et al. Ações do Conselho Federal de Contabilidade no desenvolvimento da contabilidade brasileira. Revista Contabilidade e Controladoria, v. 5, n. 2, p. 134-151, 2013. Disponível em:

https://revistas.ufpr.br/rcc/article/view/31505/21249. Acesso em: 16 out. 2018.

BRASIL. Conselho Federal de Contabilidade. Resolução no 529, de 23 de outubro de 1981. Dispõe sobre as Normas Brasileiras de Contabilidade. Rio de Janeiro: CFC, 1981a.

BRASIL. Conselho Federal de Contabilidade. Resolução no 530, de 23 de outubro de 1981. Aprova Princípios Fundamentais de Contabilidade Norma NBC-T 1. Rio de Janeiro: CFC, $1981 b$. 
GOMES JUNIOR, A. C. O ensino comercial no brasil: escola técnica de comercio Dr. Fernando Costa. 2013. 136f. Tese (Doutorado em Educação) - Universidade Metodista de Piracicaba, Piracicaba, SP, 2013. Disponível em: https://www.unimep.br/phpg/bibdig/aluno/down.php?cod=1145. Acesso em: 15 jan. 2018

GONÇALVES, M. Contabilidade por partidas dobradas: história, importância e pedagogia (com especial referência à sua institucionalização em Portugal, 17551777. De Computis: Revista Española de Historia de la Contabilidad, v. 16, n. 2, p. 69-142, 2019. Disponível em: https://dialnet.unirioja.es/servlet/articulo?codigo=7193079. Acesso em: 15 jan. 2018. HOFER, E; PELEIAS, I. R; WEFFORT, E. F. J. Análise das condições de oferta da disciplina contabilidade introdutória: pesquisa junto às universidades estaduais do Paraná. Revista Contabilidade \& Finanças, v. 16, n. 39, p. 118-135, 2005. Disponível em: http://www.scielo.br/pdf/rcf/v16n39/v16n39a10.pdf. Acesso em: 10 out. 2018.

MARRONI, C. H; RODRIGUES, A. F; PANOSSO, A. Panorama histórico do ensino superior da graduação em contabilidade no Brasil-sob a égide normativa. Enfoque: Reflexão Contábil, v. 32, n. 3, p.1-17, set-dez. 2013. Disponível em: https://www.redalyc.org/html/3071/307130918002/. Acesso em: 20 set. 2018. NIYAMA, J. K et al. Conhecimento de contabilidade internacional nos cursos de graduação em ciências contábeis: estudo da oferta nas instituições de ensino superior das capitais brasileiras. Revista de Contabilidade e Organizações, v. 2, n. 2, p. 100 117, 2008. Disponível em: http://www.revistas.usp.br/rco/article/view/34708. Acesso em: 12 out. 2018.

OLIVEN, A. C. Histórico da educação superior no Brasil. In: SOARES, M. S. A. (org.). Educação superior no Brasil. Porto Alegre: IESALC/UNESCO/CARACAS, 2002. Disponível em: http://flacso.redelivre.org.br/files/2013/03/1109.pdf. Acesso em: 20 set. 2018.

PAULA. M. F. C. USP e UFRJ: As influências das concepções alemã e francesa em suas fundações. Revista Tempo Social, v.14, n. 2, p. 147-161, 2002. Disponível em: http://dx.doi.org/10.1590/S0103-20702002000200008. Acesso em: 15 jan. 2017.

PELEIAS, I. R et al. Evolução do ensino da contabilidade no Brasil: uma análise histórica. Revista de Contabilidade e Finanças, SP, v. 18, n. especial, p. 19-32, 2007. Disponível em: http://www.scielo.br/scielo.php?script=sci_arttext\&pid=S1519$70772007000300003 \&$ Ing=pt\&tlng=pt. Acesso em: 03 de abr. 2018.

PELEIAS, I. R; BACCI, J. Pequena cronologia do desenvolvimento contábil no Brasil: Os primeiros pensadores, a padronização contábil e os congressos brasileiros de 
contabilidade. Revista Administração online (FECAP), v. 5, n. 3, p. 39-54, 2004. Disponível em: https://www.fecap.br/adm_online/art0503/art5034.pdf. Acesso em: 19 set. 2018.

RIBEIRO, M. L. S. História da educação brasileira: a organização escolar. 21. ed. Campinas: Autores Associados: 2011.

RICARDINO, Á; CARVALHO, L. N. Breve retrospectiva do desenvolvimento das atividades de auditoria no Brasil. Revista Contabilidade \& Finanças, v. 15, n. 35, p. 22-34, 2004. Disponível em: http://www.scielo.br/pdf/rcf/v15n35/v15n35a02.pdf. Acesso em: 03 out. 2018.

ROMERO, A. O sentido da reforma: o estatuto da universidade de Francisco Campos em um Brasil em transição. Campinas: Grupo HISTEDBR, 2011. Disponível em: www.histedbr.fe.unicamp.br/acer_histedbr/jornada/jornada10/_files/fo80ntlz.pdf. Acesso em: 10 de dez. 2017.

SILVA, E. C. H. Formando profissionais do comércio: uma análise do Ensino comercial brasileiro na era Vargas (1930-1945). In: ENCONTRO ESTADUAL DE HISTÓRIA DA ANPUH, 8., 2016, Santa Cruz do Sul. Anais [...] Santa Cruz do Sul: ANPUH, 2016. Disponível em: http://www.eeh2016.anpuhrs.org.br/resources/anais/46/1468531668_ARQUIVO_TextoDefinitivo.pdf. Acesso em: 01 out. 2018.

SILVA. M. A. De Portugal ao Brasil: a trajetória histórica do ensino superior de contabilidade (1940-1985): concepções e tendências relativas aos aspectos de formação dos profissionais em contabilidade. 2015. 214f. Tese (Doutorado em Educação) - Universidade Federal de Uberlândia, Uberlândia, 2015. Disponível em: https://repositorio.ufu.br/handle/123456789/19043. Acesso em: 9 maio 2018.

SOARES, S. V et al. Evolução do currículo de Contabilidade no Brasil desde 1809.

Revista Catarinense da Ciência Contábil, v. 10, n. 30, p. 27-42, ago./nov. 2011. Disponível em: http://revista.crcsc.org.br/index.php/CRCSC/article/view/1225/1157. Acesso em: 20 set. 2018.

Enviado em: 29/03/2019

Aprovado em: 25/05/2020 